\title{
"Todos los ámbitos del saber desde una mirada feminista son ámbitos sospechosos": \\ Entrevista a Lorena Fries Monleón, abogada feminista y Directora del Instituto Nacional de Derechos Humanos
}

\author{
Soledad Prieto, Catalina Lagos \\ soleprietom@gmail.com
}

Tu vasta trayectoria como abogada feminista en la defensa y promoción de los derechos humanos de las mujeres, ¿Le otorga alguna particularidad a la dirección del Instituto Nacional de Derechos Humanos (INDH)?

Lorena Fries: Yo creo que sí, porque todos los ámbitos del saber desde una mirada feminista son ámbitos sospechosos. Por lo tanto, tú miras los derechos humanos desde una sospecha. Y una sospecha que es la exclusión de las mujeres y de la mirada de las mujeres. Miras también la política desde esa sospecha, y eso hace que ése sea tu método. La sospecha es el método para avanzar en materia de derechos humanos, porque sino no sólo vas a dejar a las mujeres fuera, sino que también vas a dejar fuera todo aquello que no hace parte del derecho, y que finalmente es lo marginado.

Es como un análisis crítico...

LF: Sí. Aquí tú cruzas un análisis crítico del derecho con una mirada feminista de los derechos humanos. $Y$ en ambos casos son procesos de deconstrucción del saber que ya está establecido. Entonces, en ese sentido, me parece que sí. Luego también tienes elementos, cuestiones como más prácticas, que tienen que ver con darse cuenta cómo se legitima el poder entre los hombres y las ausencias que hay respecto de las mujeres: las mujeres no constituyen linaje, las mujeres no van armando pisos de legitimidad entre ellas, y como eso 
hace que las mujeres sean permanentemente individuas aisladas en espacios de poder más que cuerpos colectivos que van accediendo a espacios.

\section{¿Ha sido difícil instalar la perspectiva de género en el Instituto?}

LF: Es más fácil si tienes autoridad. O sea, no estás pidiendo por favor, no estás tratando de que entiendan, sino que estás diciendo lo que corresponde. $\mathrm{Y}$ en ese sentido, tener autoridad, te permite direccionar. Así fue una pelea, por ejemplo, no muy grande, pero de esas peleas que se dan donde las feministas terminamos siendo siempre como la caricatura, respecto del lenguaje inclusivo en los informes anuales: [decían] que "eso no se estila", "no se usa", "es que no lo vas a poner tan a la punta", "que no sé qué". En eso yo fui absolutamente intransable: "esto es así o yo no firmo esta cuestión". Pero tienes mucho todavía que pelear, mucha cosita chica que pelear. Eso por una parte.

Un segundo aspecto que también quizás es complejo, es que esta es una institución en que hay más mujeres que hombres, y eso es visto con sospecha. Pero no es visto con sospecha si esta institución tiene más hombres que mujeres. Entonces, eso es algo que también tú tienes que estar permanentemente deconstruyendo. Porque pareciera que lo normal, lo objetivo y lo neutral es efectivamente lo masculino, que es la crítica que uno puede hacerle al derecho y también a cómo están conformadas las relaciones de género.

Y entre otras autoridades del Estado, por ejemplo en el poder ejecutivo, legislativo y judicial, ¿cómo ha sido visto el Instituto Nacional de Derechos Humanos y la perspectiva de género?

LF: Yo creo que en los otros poderes del Estado hay un gradual reconocimiento de la labor del Instituto. En el parlamento de todas maneras. En el poder judicial estamos empezando. Claramente no son espacios amigables para la perspectiva feminista. Lo que una puede decir es que si no estuviera esta perspectiva, se retrasaría todo mucho más. Entonces, hay una negociación que una tiene que hacer consigo misma, que tiene que ver con que hay algo en la cultura de género establecida que te permite soslayar algunos problemas, 
y por lo tanto, que hay que utilizarlo. Por ejemplo, una cultura muy machista no se va a agarrar a garabatazos con una mujer, aun cuando esté diciendo exactamente lo opuesto, y eso te permite, digamos, seguir adelante. Pero son estos privilegios entre comillas que supuestamente tenemos, porque no nos pueden tocar ni con el pétalo de una rosa.

¿Consideras en ese sentido que hay poca consciencia de las obligaciones internacionales que pesan sobre el Estado de Chile?

LF: Yo creo que hay poca, y creo además que recién nos estamos empezando a abrir. Porque aquí desarrollamos la cultura de derechos fundamentales a partir de la Constitución del 80. Esa Constitución y todo lo que la rodeaba, miraba de manera amenazante al mundo internacional. Y, por lo tanto, eso nunca fue parte del estudio, y hoy día [así] sigue siendo mayoritariamente: por lo menos el 50\% siguen siendo cursos electivos. Por lo tanto, no se aprende cuáles son las obligaciones del Estado, cómo concretarlas, no se aprende qué es el principio de igualdad y no discriminación, las medidas afirmativas, qué significa eso... No hay un conocimiento del derecho internacional en general en las Universidades. Y si no lo hay en las Universidades, no lo tienen los profesionales. Y finalmente la gente que está metida en el mundo de los derechos humanos desde una lógica más internacional, ha recibido prácticamente autoformación. $\mathrm{Y}$ eso te mantiene todavía en la marginalidad del conocimiento académico.

El INDH desde que comenzó ha recibido varias críticas en cuanto a su autonomía o lo politizado o no que está. ¿Cuál es la posición que tienen ustedes respecto a esas críticas?

LF: Yo creo que en principio uno tiene que decir, bienvenidas las críticas. El punto es que hay que hacerlas con rigurosidad y con buenas intenciones. Y yo creo que las críticas hacia el Instituto no han sido ni rigurosas respecto a la metodología con que se afirman ciertas cosas, ni han sido bien intencionadas. Entonces, por supuesto que hemos salido en respuesta de ello. Y sobre todo, lo que hay de fondo es un sistema perverso binominal, que no acepta que haya otras coordenadas que no sean las binominales. Y el punto es que 
este Instituto tiene una conformación que se escapa del binominal por la presencia de organizaciones de la sociedad civil, que yo creo que hacen que este Instituto sea lo que tiene que ser, porque así lo establece el sistema de las Naciones Unidas de acuerdo los Principios de París. Pero además porque esta es una sociedad que ha devaluado muchísimo el aporte que han hecho las organizaciones de la sociedad civil a la promoción y a la protección de los derechos humanos. Entonces la verdad es que esas críticas no nos llegan como Institución.

Respecto al proyecto de crear una Subsecretaría de DDHH, ¿cómo lo evalúan ustedes?

LF: Nosotros estamos a favor de que haya una Subsecretaría. Punto uno, el proyecto tiene que ser reformado en el sentido de incluir ciertas cosas que no están y evitar confusiones que ahí se establecen. Pero qué duda cabe que todo órgano del Estado debiera tener una instancia que te permita coordinar, diseñar y ejecutar políticas en materia de derechos humanos. Lo tiene el congreso: las comisiones de derechos humanos de diputados y senadores. El poder judicial no lo tiene, pero en otros países hay poderes judiciales que sí lo tienen y uno debiera avanzar hacia eso. Y el poder ejecutivo no lo tiene, siendo que es el que ejecuta las políticas públicas. Por lo que me parece muy bien que exista. El punto [es] que a esa Subsecretaría tú le puedes dar más o menos peso. Nosotros queremos que se le dé peso y que ese peso signifique que coordine no sólo lo que viene para adelante, sino que también coordine la políticas de reparación en este país, y eso significa además dejar una puerta abierta para seguir calificando a víctimas que tienen derecho a reparación en la medida que van saliendo juicios. Eso no está en el proyecto. Lo segundo que nos parece, es que debiera haber un vínculo más estrecho entre el Plan Nacional de Derechos Humanos y la consulta a la sociedad civil, la que no está muy claramente establecida. Y lo tercero, es dejar explicitado la total independencia del Instituto frente a esta estructura. Porque la verdad es que en el mensaje estamos dentro del sector de justicia y después pareciera que vamos a quedar amarrados a tener que presentarle cuestiones a la Subsecretaría y nosotros tenemos un registro que es todo el Estado... Esas son las 
principales críticas, pero [de] que hay que tener una Subsecretaría, hay que tenerla.

Recientemente fue el examen de Chile ante el Comité para la Eliminación de la Discriminación contra la Mujer (CEDAW). ¿Cuáles fueron las mayores preocupaciones que planteó el Comité y cómo reaccionó el Estado?

LF: A mí me pareció que dentro de los exámenes que yo he visto de Chile ante la CEDAW, éste fue uno de los más completos. Fue más completo tanto de parte de las miembras del Comité, como de parte del Estado chileno. En ese sentido yo creo que hay un ejercicio de darle importancia a una instancia, cuestión que antes no se le daba. Muchas veces era el mismo funcionario de la embajada el que terminaba yendo al Comité, o con unas delegaciones muy chicas que no daban cuenta de la transversalidad que tiene el tema en el Estado. Desde ese punto de vista, me pareció interesante. Me pareció interesante también que metieran una duda teórica de este uso que hace el Estado chileno sobre el tema de la equidad como si fuera sinónimo de la igualdad, y me parece que por ahí hay una confusión en este país entre ambas cosas, [en el sentido de] que la igualdad es a la no discriminación, como la equidad es a la pobreza. Y en ese sentido, me parece que todavía no terminamos aún de armar el marco de derechos para abordar, por ejemplo, los temas que tienen que ver con discriminación socioeconómica. Por lo tanto ese llamado de atención me pareció bueno.

Lo otro a mí me parece que son los temas de siempre. A lo que se suma, esta vez, todo lo que ha sido los temas de violencia policial, los temas de trata y de migrantes. Pero los otros temas son los que han estado en el tapete casi siempre para nosotros, que son los temas de violencia, los temas de participación, los temas de trabajo. Entonces, yo creo que persiste la preocupación, al final, por el modelo de desarrollo en Chile y cómo afecta a las mujeres. Sobre todo con un tema de encrucijada total, que es la famosa corresponsabilidad, y eso también lo toca el Comité y exhorta al Estado a avanzar en la corresponsabilidad. Pero claramente eso va más allá de tener un postnatal más corto o más largo, sino que tiene que ver con la democratización de la esfera privada, y ahí yo creo que todavía no estamos en ese debate. 
Y en temas que se repiten por segunda o tercera vez en el Comité CEDAW, como la baja participación política de las mujeres o el tema del aborto, donde el Comité vuelve a insistir, ¿qué responde el Estado?

LF: Yo creo que el Estado con el aborto no transa. Lo ha dicho públicamente, lo ha dicho en todos lados. Entonces sobre ese punto mientras no haya un impulso más decidido acá adentro, no le van a hacer caso al Comité, y ahí esgrimen desde soberanía hasta la legitimidad que tiene el Estado para establecer los tiempos y los momentos en que avanzan. Y en el tema de participación política, tienes un resultado concreto que es la propuesta que presentó la Ministra Schmidt sobre participación de las mujeres. Podrá a uno gustarle o no, pero es una respuesta a lo que ha dicho varias veces el Comité, sobre todo porque en este país la idea de igualdad no está ligada a la diferencia y a las medidas de acción afirmativas. Acá existe una igualdad pinochetista que es todos somos iguales a, asimilados a, la conducta más hegemónica, al varón en edad reproductiva, blanco, heterosexual, etc.; eso es lo que recién empieza a resquebrajarse en el modelo de convivencia chilena y yo creo que eso es lo que hace que se presente un proyecto como éste, que antes no logró ver luz.

Continuando con la materia del aborto, tomando en consideración la reciente propuesta del "bono a madre adolescente" por un lado, y el nuevo proyecto de aborto terapéutico, ¿cuáles son las mayores dificultades de instalar el debate y avanzar en materia de derechos sexuales y reproductivos?

LF: La relación entre verdad y tolerancia. En este país todavía hay demasiada gente que cree que tiene la verdad, y la verdad lamentablemente se opone a la tolerancia, porque la tolerancia es admitir que no hay verdades absolutas y que tú necesitas llegar a ciertos consensos y mayorías para ir estableciendo cuales con las verdades; no hay verdades esenciales ni metafísicas. Por lo tanto, me parece que el que todavía una gran cantidad del país viva en una lógica de una verdad absoluta y en una especie de comunitarismo, en el sentido de que uno nace en una posición y muere en esa posición, es lo que atenta, lo que al final uno diría que es el autoritarismo, lo que atenta la posibilidad de establecer y abrir ciertos temas, en un momento que de todas maneras creo que es de inflexión. No 
estamos como hace diez años, yo supongo que alguien va a decir algo distinto en el período que viene.

En unos pocos meses más nos toca un nuevo Examen Periódico Universal. ¿Cuáles crees tú que son las prioridades en materia de derechos para las mujeres que se tienen que instalar en este nuevo ciclo?

LF: Sí o sí, violencia y participación política. Creo que el otro tema que es más complejo, es trabajo y corresponsabilidad, y lo que hace a la libertad de las mujeres, que es el derecho al cuerpo. 